\title{
RETURNS AND PERSISTENCE OF INVESTMENT FUND PERFORMANCE IN THE CZECH REPUBLIC
}

\author{
Dariusz Filip*
}

\begin{abstract}
:
The article aims at verifying the occurrence of performance persistence phenomenon among equity funds in the Czech Republic. The study uses the most popular measures of return mentioned in financial academic publications. Moreover, a relatively long time horizon, lasting from the beginning of 2000 to the end of 2010 was taken into consideration. The non-parametric methods utilized in the study were traditional contingency tables combined with a new approach discussed in the literature on the subject and related to the estimation of stochastic kernel. The obtained results have revealed the existence of weak and limited performance persistence within the total time horizon and in several sub-periods. The significance of the phenomenon depended on the applied measure of return. Furthermore, performance dependence in successive periods was related to the market situation. In general, the character of the occurrence of performance persistence may be connected with the size and the level of development of the Czech investment fund industry.
\end{abstract}

Keywords: investment funds, performance persistence, CEE markets

JEL classification: G11, G23, G29

\section{Introduction}

In the space of the last 50 years, the global mutual fund industry has experienced a dynamic growth. Collective investment institutions existing in the emerging markets have received a considerable inflow of assets over the past 15 years. This tendency was changing at the time of decline in economic situation. However, an inflow of assets to these financial institutions can be observed again in the Central Eastern European markets. According to the European Fund and Asset Management Association (EFAMA, 2011), at the end of 2010 the value of the Bulgarian, Czech, Hungarian, Polish, Romanian, Slovak and Slovenian fund industries was calculated to be EUR56,392 million, which is $0.7 \%$ of the net asset value of the European investment fund industry. The value of assets of the Czech investment funds at the end of the time horizon of the study amounted to EUR 4,883 million, which in relation to 2000 (EUR2,112 million) is equivalent to an increase by $131 \%$. Unfortunately, the low values of assets trusted by the collective investment institutions from the CEE countries show that the competition opportunities of these

Cardinal Stefan Wyszynski University in Warsaw (UKSW) Woycickiego Str. 1/3 bl. 3 01-938

Warsaw, Poland (d.filip@uksw.edu.pl). 
entities in the European market are limited; nonetheless, the dynamics of increase in values gives hope for their further development. However, the Czech investment fund market seems to be underestimated compared to other financial organisations (banks or pension funds) in the country at the moment.

Since the publication of the first papers by Sharpe (1964) or Lintner (1965), the research approaches to investment returns have evolved along with the development of the collective investment institutions. The previous studies regarding the effects of mutual fund management focused mainly on establishing ways to measure returns or finding persistence in outperformance. At present, the surveys related to the monitoring the performance in collective investment institutions raise three major issues. Firstly, they verify the hypotheses about obtaining outperformance and about the occurrence of its persistence. Secondly, they try to explain the reasons for the emergence of these phenomena especially from the managerial skills perspective. Thirdly, they try to establish the relation existing between the received returns (or other internal factors) and asset in- and outflow of funds.

Among the recipients of the analyses regarding the issue of performance persistence phenomenon of mutual funds, there are not only individual investors but also asset management companies. From the perspective of an organization, the analyses within this scope help to determine whether the organizational and HR solutions applied by the asset management companies are efficient or not. Moreover, the information on high values of returns and on winning persistence may be particularly useful for the management staff as far as marketing reasons are concerned. From the perspective of investors, the results of performance persistence examination may form their outlook on the achieved fund returns and the managerial skills of fund managers, and thus influence their investment decisions. Furthermore, the researchers dealing with this issue may determine the character of the possible performance dependence in successive periods, which enables them to evaluate the intensity of competition in the branch, for instance.

The aim of the study is to continue the research into the performance of the Czech-based investment funds and to supplement the results of the sparse analyses made so far by providing further observations concerning the issue in question. The practical goal of the paper is to establish whether the performance of collective investment companies is characterized by persistence, which is a piece of knowledge that may be especially important for investors and fund managers. Furthermore, the verification of the null hypothesis about the lack of performance dependence in consecutive periods by means of selected research methods shall fill the gap existing in the Czech research.

The remainder of the article is organized as follows. The next section reviews the financial literature concerned with the research-related topics. The features of the collected data and the adopted methodological approach are presented in Section III. Section IV presents the empirical results obtained from the fund performance analysis. The paper ends with a conclusion. 


\section{Review of the Literature}

Many research papers on investment theory discuss the issue of creating measures of return. They try to show fund performance in a transparent way, while taking expected return for a particular risk level into consideration. The early research that exploited the CAPM model to determine the dependence between the included risk and the rate of return was based on the intercept and slope coefficients of relatively fixed regression models (see Jensen, 1968). As a result, it was possible to set up standards for the effectiveness evaluation of the decisions made by fund managers (see e.g. Treynor and Mazuy, 1966 or Hendriksson and Merton, 1981). Other researchers, such as Sharpe (1964) or Treynor (1965) developed the ways of measuring returns by using systematic risk. The ratios proposed at that time entered the canon of effectiveness measures of management in collective investment institutions.

The multifactor models, which are an extended version of the traditional CAPM model, made it possible to consider specific variables relating to a particular market situation (Fama and French, 1993) or the macroeconomic data (Ferson and Schadt, 1996), while analyzing performance. This meant another stage of research concerning the measures of return on investment. Finally, the four-factor model, proposed by Carhart (1997), taking fundamental factors as well as the so-called "momentum effect" into account, has been popularized to performance evaluation of investment funds in the last years.

Performance - presented in academic studies from various perspectives - has been utilized for the analyses of the dependence of investment effects. One of the topics frequently discussed in the US financial literature over the last 20 years has been the phenomenon of performance persistence. One of the most significant papers concerning this issue is the study of Brown and Goetzmann (1995). The researchers found the existence of 1-year performance persistence in US equity funds by the application of the methods referred to as traditional ones by the literature of the subject (the so-called contingency tables). They made it clear, however, that the examined phenomenon is strongly dependent upon the time period of study for the raw returns, CAPM alpha, Treynor-Black appraisal ratio and three-index appraisal ratio.

Just like in any other dispute, the concept of persistence has its adherents and opponents. The findings of Gallo, Lockwood and Swanson (1997) were not favourable to the discussed phenomenon. In this case, the analyzed entities were the US-based international bond mutual funds. In the total period under study, they were not able to maintain their group affiliation related to the distribution of the Sharpe ratios, Jensen's alphas and ratios of multi-index model. They were also unable to consequently outperform benchmarks.

The papers discussed in the following part of this section were selected with regard to the number of return measures incorporated by their authors. Thus, Bers (1998) engaged in a long-term performance persistence examinations. The traditional rate of returns as well as the Jensen, Sharpe and Treynor ratios were calculated based on unit shares of the US-based international mutual funds. Bers found the evidence for the occurrence 
of performance persistence using parametric and non-parametric tests. Moreover, the findings became more reliable with the extension of the time-horizon of the study. Furthermore, Madura and Bers (2002) tried to perform the persistence analysis of net assets values of international closed-end equity funds in 12-, 24- and 36-month periods by means of multifactor version of the Jensen model as a measure of abnormal returns. Having divided the funds into winners and losers based on their asset management effects, Madura and Bers found out that performance persistence exists for winning funds over long periods. In the case of losers, the researchers obtained statistically significant performance reversal within 1-year perspective. This was caused by the fact that the losing funds frequently changed their investment strategies in the preceding periods, which lead to the improvement of their performance in the successive ones.

The wide spectrum of methods to measure the return of collective investment institutions has been used by Christensen (2005). In his study concerning Danish equity and fixed income funds, he carried out the effectiveness evaluation of their performance. By using the single index regression model and the multi-factor model of Treynor-Mazuy to appraise the asset selection ability and by following the methodological approach proposed by Hendriksson-Merton for the verification of market timing skills, he did not find any sufficient evidence for the existence of managerial skills connected with achieving outperformance. Furthermore, he was unable to prove the occurrence of performance persistence in Danish mutual funds by the application of parametric and nonparametric methods.

In the financial literature, we can also encounter other approaches towards the examination of the influence of fund characteristics on achieving performance, which are at the same time related to the analysis of performance persistence. While examining the US equity funds performance, Detzel and Weigand (1998) took into account fund internal factors such as expense ratio, size, book-to-market ratio, earnings yield and cash flow field. They noticed that investors who selected the best-performing funds from prior period to their portfolios, should also consider the size of stocks held by the funds as well as the style characteristic of funds to expect good results in successive periods. However, the study of Otten and Bams (2002) on the European equity funds from the UK, France, Germany, Italy and the Netherlands underlines the influence of determinants such as fund's age, expense ratio and total fund asset value on performance. The researchers used in their study the four-factor Carhart's model to assess abnormal returns. They obtained strong evidence for the occurrence of performance persistence but only in a few groups of funds existing in the European markets.

The comparable studies on performance persistence in the CEE countries were undertaken very occasionally. Until now, the Czech investment funds were analyzed mainly in terms of abnormal returns (e.g. Jindrichovska, 2009). The study by Filip (2011) incorporating the rate of returns, Jensen alphas and Carhart's measures for the Czech equity funds in the period from 2004 to 2010, did not provide statistically significant evidence for the existence of results that could considerably outperform a benchmark. The performance 
dependence in consecutive sub-periods, which was additionally investigated in that study by means of regression and correlation analyses, was hardly observed in the examined 1 -year periods.

\section{Data and Methodology}

The data essential for the calculation of particular measures of returns come from the database originally constructed by Filip (2011) for the effectiveness assessment of Czech investment funds management. However, this study, as compared to the previous one, deals with a longer time-horizon, the extension of which was meant to provide for a larger number of observations. Hence, the analyzed period - from the beginning of 2000 to the end of 2010 - will make it possible to consider the main issue of the present study in a long term. Moreover, the list of 33 open-end funds classified as equity funds (25) and funds of funds (8) was selected for the analysis from the Czech Capital Market Association's (AKAT CR) database on collective investment institutions. The latter type of funds was restricted only to the equity-specific ones so as to maintain the same fund category of investment policy. The investment area criterion applied to the chosen funds was connected with domestic and global stock markets. Since the number of funds operating in the Czech Republic is very limited, drawing any conclusions having separated smaller sub-groups of funds with the same geographical risk profile would be unreasonable. The monthly performance served as a starting point for further assessment.

The present paper will investigate the basic measures of returns and their use for persistence analysis. From among the classic risk-adjusted measures, the author decided to choose the logarithmic rate of return, Sharpe ratio and Treynor ratio. Due to the lack of statistical significance of the Jensen alphas and Carhart's measure, revealed in the study of Filip (2011), the mentioned measures of return were excluded from this study.

The most popular measure of investment effects used in financial analyses is the rate of return, which is based on the values of funds' units share and it can be calculated logarithmically as follows:

$$
Y_{t, i}=\ln \left(\frac{N A V_{t, i}}{N A V_{t-1, i}}\right)
$$

where $Y_{t, i}$ is the rate of return on fund $i$ in the period $t, N A V_{\text {tor } t-1, i}$ are the net asset values per unit on fund $i$ in the analyzed period $t$ or in the preceding period $(t-1)$ for all time perspectives.

The second measure used in this study, proposed and revised by Sharpe, shows the differences in the level of undertaken risk by means of standard deviation. The rewardto-variability ratio (the so-called Sharpe ratio) is calculated as follows (Sharpe, 1966): 


$$
S R_{t, i}=\frac{Y_{t, i}^{a v}-r_{f}}{\sigma\left(Y_{t, i}\right)}
$$

where $S R_{t, i}$ is the Sharpe ratio on fund $i$ in the period $t, Y_{t, i}^{a v}$ is the mean monthly rate of return achieved over the period $t$ by fund $i, r_{f}$ is the mean risk-free return over the analogous period, $\sigma\left(Y_{t, i}\right)$ is the standard deviation of the monthly rate of return on fund $i$ and it can provide the information about systematic and idiosyncratic risks.

The last measure used in this study, the reward-to-volatility ratio (the so-called Treynor ratio) is equally popular as the ones mentioned above. It is similar to the previously mentioned measure in terms of its construction. This measure including systematic risk was provided by Treynor (1965) and can be computed as follows:

$$
T R_{t, i}=\frac{Y_{t, i}^{a v}-r_{f}}{\beta\left(Y_{t, i}\right)}
$$

where $T R_{t, i}$ is the Treynor ratio on fund $i$ in the period $t, Y_{t, i}^{a v}$ is the mean monthly rate of return achieved over the period $t$ by fund $i, r_{f}$ is the mean risk-free return over the analogous period, $\beta\left(Y_{t, i}\right)$ is the Beta of fund $i$ and stands for the measure of systematic risk. The Sharpe ratio and the Treynor ratio are calculated for the same periods as the rates of return.

As for the research methods, the study will adopt a traditional approach to the existence of performance persistence and evaluation of its strength, which is namely the CrossProduct Ratio's (CPR) analysis. The CPR was proposed by Fienberg (1980) to test whether the results from subsequent periods are independent form each other. This can be done by the application of $2 \times 2$ contingency tables. In order to use this method, it is crucial to take the median of fund returns as a criterion of classification and divide all the analyzed funds into two groups: good performers (W) and bad performers (L). Hence, the CPR means the ratio of the number of funds that repeat performance (WW, LL) in the two successive periods to the number of the ones that do not (WL, LW) and is calculated as follows (Jackowicz et al., 2011):

$$
C P R=\frac{W W * L L}{W L * L W}
$$

A CPR of one, in this form, gives no grounds to reject the null hypothesis about the independence of performance in consecutive periods. A ratio greater than one indicates performance persistence, whilst a ratio lower than one means a predominance of reversals in performance. Determining the number of entities qualified to the respective groups in relation to their results in the two successive periods is essential to calculate the asymptotic standard error of the natural logarithm of the CPR. It will be used in the further part of the paper and can be calculated as follows (Christensen, 1990):

$$
\sigma_{\ln (C P R)}=\sqrt{\frac{1}{W W}+\frac{1}{W L}+\frac{1}{L W}+\frac{1}{L L}}
$$


The statistical significance of the CPR can then be determined by the $Z$-statistic, which is computed as the log of CPR divided by its standard error (Hallahan, 1999):

$$
Z=\frac{\ln (C P R)}{\sigma_{\ln (C P R)}}
$$

The next test of performance independence is the chi-square test with one degree of freedom. It is also based on the contingency tables and the $\mathrm{CHI}$-statistic is calculated as follows (Kahn and Rudd, 1995):

$$
C H I=\sum \frac{\left(O_{i}-E_{i}\right)^{2}}{E_{i}}
$$

where $O_{i}$ is the observed number of funds in each performance group (WW, LL, WL and LW) established on the basis of the median of returns and $E_{i}$ is the expected number of funds in each group. The calculated value of the $C H I$-statistic is always positive, so it is unable to indicate reversals in performance. Hence, the $\mathrm{CHI}$-statistic ought to be considered directly with the CPR.

The second research method applied in this paper is the stochastic kernel estimation. The kernel estimation procedure is a technique still rarely used for analyzing performance dependence of financial institutions. The kernel estimators, proposed at the turn of the 1950s and 1960s, are used in life, medical and technical sciences. The first studies in economics employing this method date to the mid-1970s and concern macroeconomic issues, such as the distribution of household income (Lillard and Willis, 1978).

The stochastic kernel is a graphical representation of transition matrices with a number of initial descriptions of the stochastic process tending to infinite. By using this method, it is possible to receive information about the probability of transition between the successive levels in the range of values of random variable (cf. Quah, 1997; De Jorge, 2006).

The stochastic kernel estimation is a nonparametric technique of appraising the density function of the conditional probability distribution of a random variable $(X(t+1) \mid X(t))$ based on the value of variable achieved in the period $t+1$ corresponding to the value in the previous period $(t)$. The estimator of the mentioned density function $f(x(t+1) \mid x(t))$ may be defined as (Jackowicz and Kozłowski, 2008):

$$
\hat{f}(x(t+1) \mid x(t))=\hat{g}(x(t), x(t+1)) / \hat{h}(x(t))
$$

where $\hat{g}$ is the estimator of the density function of a variable $(X(t), X(t+1))$, and $\hat{h}$ means the estimator of density function of a variable $X(t)$.

One of the main dilemmas during the application of this method is the choice of bandwidths parameters. In this connection, there is a possibility of data smoothing, which is a fundamental problem in an investigation (see Scott, 1992). Hence, in this study, the author decided to use a version of the Rosenblatt's (1969) estimator modified by Hyndman et al. (1996), where bandwidths are a trade-off between bias properties 
and variance:

$$
\begin{aligned}
& \hat{g}(x(t), x(t+1))= \frac{1}{n a b} \sum_{i=1}^{n} K_{2}\left[\left(\frac{\left|x(t)-x_{i}(t)\right|}{a}\right)\left(\frac{\left|x(t+1)-x_{i}(t+1)\right|}{b}\right)\right] \\
& \hat{h}(x(t))=\frac{1}{n a} \sum_{i=1}^{n} K_{1}\left(\frac{\left|x(t)-x_{i}(t)\right|}{a}\right)
\end{aligned}
$$

where $K_{2}$ is the two-dimensional probability density function, while $K_{1}$ is the function of one-dimensional probability density, $a$ and $b$ are bandwidths parameters.

The results of applying kernel estimation will be presented in the form of a graphic interpretation of two types of diagrams simultaneously. The first one represents a threedimensional space. The $\mathrm{X}$-axis shows the values of performance reported in periods $t+1$. The Y-axis will present the values from the period $t$, while the Z-axis plots the density function $f(x(t+1) \mid x(t))$ defined above. The stochastic kernel mapping, which presents the transition probability of successive fund returns, is similar to a hypsometric map depicting the configuration of a land's surface. The particular lines on the contour of the stochastic kernel's ridge include points at the same height, which means the transition probability. The main element of the contour can be called a ridge of the stochastic kernel. The second scheme of a stochastic kernel's representation, which uses two-dimensional space with $\mathrm{X}$ - and Y-axis, enables the graphic interpretation of the kernel's location in relation to the line inclined at an angle of 45 degrees to the $\mathrm{X}$-axis.

The stratification of the stochastic kernel along the mentioned line both in $3 \mathrm{D}$ and $2 \mathrm{D}$ spaces means a low degree of performance mobility in consecutive periods, which can support the thesis about the occurrence of persistence. The slight clockwise rotation of the kernel's ridge in relation to the diagonal of the contour implies the intensification of disparity in the performance of funds, which means the appearance of winning and losing persistence. The counter-clockwise rotation of the kernel's ridge in relation to the diagonal is equivalent to the existence of performance convergence among the analyzed entities. A perpendicular stratification of the stochastic kernel in relation to the line inclined at an angle of 45 degrees to the $\mathrm{X}$-axis indicates a performance reversal tendency in successive periods.

The confrontation of the research findings achieved by the application of the classic method with the ones obtained by adopting a new unconventional approach to the analysis of performance persistence seems to be an interesting issue for the study. An additional argument for using stochastic kernel estimation is the lack of necessity to provide the so-called discretisation process, which consists in transforming a continuous variable into a discrete one. As a result, there is no necessity to simplify the data, and thus a partial loss of the information included in the dataset is avoided. Furthermore, the application of a technique which allows performance analysis, but is still rarely discussed in financial literature, expands the catalogue of research procedures in this area. 


\section{Empirical Results}

The empirical results will be presented in a particular order. The findings connected with the time perspective that exceeds three years will be presented in the first place as introductory to the issue of persistence. The actual empirical part discussing both the adopted research methods will focus on one-year perspective. This will be followed by a sub-section on the six-month horizon, which vividly shows the moments relevant for performance dependence in consecutive periods. The part concerning the situation in the Czech financial market, directly following the empirical results form the six-month perspective, will refer to all the findings described in this section.

\subsection{Three-year-plus perspective}

A long-term investment time perspective allows to run tests with a lower risk of obtaining extreme results. However, while analyzing long periods, it is crucial to have an appropriate number of observations necessary to receive reliable results. The requirements related to a long perspective in the analysis of investment funds in the Czech Republic limit the possibility of using stochastic kernel estimation as a method of investigating performance dependence in consecutive periods due to a low number of observations. Thus, the results from this part should be treated as preliminary ones.

Table 1

Results of Non-parametric Tests Based on Contingency Tables in 3-Year-plus Perspective

\begin{tabular}{|l|c|c|c|c|c|c|c|c|c|c|}
\hline Measure & \multirow{2}{*}{$\begin{array}{c}\text { No. of } \\
\text { observ. }\end{array}$} & \multicolumn{3}{|c|}{ Rate of Return } & \multicolumn{3}{c|}{ Sharpe Ratio } & \multicolumn{3}{c|}{ Treynor Ratio } \\
\hline Periods & $\mathbf{C P R}$ & $\boldsymbol{Z}$ & $\boldsymbol{C H I}$ & $\boldsymbol{C P R}$ & $\boldsymbol{Z}$ & $\boldsymbol{C H I}$ & $\boldsymbol{C P R}$ & $\boldsymbol{Z}$ & $\boldsymbol{C H I}$ \\
\hline $\begin{array}{l}\mathbf{2 0 0 7 - 2 0 0 4 /} \\
\mathbf{2 0 0 3 - 2 0 0 0}\end{array}$ & 6 & 0,00 & $n c$ & 2,0000 & $n c$ & $n c$ & $* 3,3333$ & $n c$ & $n c$ & $* * 3,8571$ \\
\hline $\begin{array}{l}\mathbf{2 0 1 0 - 2 0 0 8 /} \\
\mathbf{2 0 0 7 - 2 0 0 4}\end{array}$ & 14 & 0,30 & $-1,0628$ & 1,4286 & 0,50 & $-0,6200$ & 0,8571 & 1,00 & 0 & 0,2857 \\
\hline $\begin{array}{l}\text { total horizon } \\
\mathbf{2 0 0 0 - 2 0 1 0}\end{array}$ & 20 & 0,24 & $-1,4283$ & $* 2,8000$ & 1,40 & 0,3665 & 1,2000 & 2,63 & 1,0726 & 1,2857 \\
\hline
\end{tabular}

Note: ${ }^{*},{ }^{* *},{ }^{* * *}$ indicate statistical significance to reject the null hypothesis at respective levels: $10 \%, 5 \%$ and $1 \%$. The $n c$ symbol was used because of the lack of mutual funds classified to the WL or LW groups, which did not allow for calculation of CPR or Z-statistic. Source: own study.

The three-year-plus time perspective based on a mere 20 observations concerning the whole period under study provides the initial results about the lack of performance persistence. Similar categories of appraisals with regard to the criterion of returns median were observed extremely rarely. However, by means of the CHI-statistic, it is possible to observe a very weak persistence of the Sharpe ratios and Treynor ratios in the 2007-2004/2003-2000 sub-period and of the rates of return in the total period of study. As mentioned before, the second method may be used for the returns from the total period but only in one-year and six-month time perspectives due to the requirements concerning the 
number of observations indispensable to obtain the credible estimations of a stochastic kernel's shape. Finally, the next parts of the analysis will provide conclusions about the existence of the investigated phenomenon.

\subsection{One-year perspective}

The empirical results presented in this part of the study were obtained by the application of two research methods. The findings received by means of contingency tables (the method viewed as traditional by financial literature), which allow to run two tests for independence, constitute a starting point for the research part proper. Here again, the applied measures of return were the rates of return, Sharpe ratios and Treynor ratios. As mentioned in the methodological section of the paper, due to their statistical insignificance for the Czech investment funds analyzed in one-year periods, Jensen alphas and Carhart's measures are considered by the author to be redundant as far as further investigation of persistence or performance reversals is concerned.

Table 2

Results of Non-Parametric Tests Based on Contingency Tables in 1-Year Perspective

\begin{tabular}{|c|c|c|c|c|c|c|c|c|c|c|}
\hline Measure & No. of & & Rate of Ret & & & Sharpe $\mathbf{R}$ & & & Treynor R & \\
\hline Periods & observ. & $C P R$ & $z$ & $\mathrm{CHI}$ & $C P R$ & $Z$ & $\mathrm{CHI}$ & $C P R$ & $z$ & $\mathrm{CHI}$ \\
\hline $2001 / 2000$ & 9 & 0,50 & $-0,4709$ & 1,2222 & $n c$ & $n c$ & $* * * 5,6667$ & 0,22 & $-1,0218$ & 1,2222 \\
\hline $2002 / 2001$ & 18 & 64,00 & $* \star * 2,7726$ & $* * * 10,8889$ & 1,60 & 0,4822 & 1,1111 & 12,25 & **2,2097 & $* \star 5,5556$ \\
\hline $2003 / 2002$ & 17 & 1,25 & 0,2289 & 0,1765 & 3,75 & 1,2508 & 2,0588 & 0,48 & $-0,7402$ & 0,6471 \\
\hline $2004 / 2003$ & 15 & 18,00 & ${ }^{* *} 2,1347$ & $* * 5,5333$ & 42,00 & ${ }^{* *} 2,4595$ & $* * * 8,2000$ & 7,50 & *1,7235 & ${ }^{*} 3,4000$ \\
\hline $2005 / 2004$ & 14 & 0,30 & $-1,0628$ & 1,4286 & 1,00 & 0,0000 & 0,2857 & 0,30 & $-1,0628$ & 1,4286 \\
\hline $2006 / 2005$ & 14 & 6,25 & 1,5488 & 2,5714 & 6,25 & 1,5488 & 2,5714 & 6,25 & 1,5488 & 2,5714 \\
\hline $2007 / 2006$ & 14 & 6,25 & 1,5488 & 2,5714 & 6,25 & 1,5488 & 2,5714 & 0,56 & $-0,5327$ & 0,2857 \\
\hline $2008 / 2007$ & 16 & 0,36 & $-0,9892$ & 1,0000 & 1,67 & 0,5025 & 0,5000 & 0,60 & $-0,5025$ & 0,5000 \\
\hline $2009 / 2008$ & 21 & 0,02 & ${ }^{* * *}-2,8204$ & $* * * 10,8095$ & 0,06 & *** $-2,5997$ & $* * * 8,1429$ & 0,10 & ${ }^{* *}-2,2550$ & ${ }^{* *} 6,2381$ \\
\hline $2010 / 2009$ & 25 & 1,63 & 0,6074 & 0,4400 & 4,50 & *1,7531 & *3,3200 & 4,50 & *1,7531 & ${ }^{*} 3,3200$ \\
\hline $\begin{array}{l}\text { in period } \\
2000-2007\end{array}$ & 101 & 3,55 & $* * * 3,0239$ & ${ }^{* * *} 9,8515$ & 4,67 & $* * * 3,5963$ & $* * * 13,6535$ & 1,54 & 1,0794 & 1,5347 \\
\hline $\begin{array}{l}\text { in period } \\
2007-2010\end{array}$ & 62 & 0,35 & ${ }^{* *}-2,0095$ & **4,1935 & 0,88 & $-0,2540$ & 0,0645 & 0,77 & $-0,5079$ & 0,3226 \\
\hline $\begin{array}{l}\text { total horizon } \\
2000-2010\end{array}$ & 163 & 1,44 & 1,1623 & 1,6871 & 2,39 & *** 2,7217 & $\star \star \star * 7,5767$ & 1,19 & 0,5460 & 0,4601 \\
\hline
\end{tabular}

Note: ${ }^{*}{ }^{* *},{ }^{* *}$ indicate statistical significance to reject the null hypothesis at respective levels: $10 \%, 5 \%$ and $1 \%$. The $n c$ symbol was used because of the lack of mutual funds classified to the WL or LW groups, which did not allow for calculation of CPR or Z-statistic. Source: own study.

The two statistical tests based on contingency tables applied during the examination of the annual performance of equity funds in the Czech Republic provided only a partial evidence for the existence of the analyzed phenomenon in the total period under study. This was possible to be observed exclusively by means of the Sharpe ratio. The applied measures have revealed to a various extent, in the case of periods of well-defined market 
trends (especially 2002/2001 and 2004/2003) that the fund group affinity (being a winner or loser) in the successive period is determined by the one from the preceding period. However, there was a reversal in this tendency in 2009/2008 when the winners were replaced by losers (and another way around) in performance distribution. This might be directly related to the effects of the appearance of financial crisis, which meant a dynamic change in the trend at that time. Therefore, the findings obtained by considering only two separate sub-periods within the whole time horizon of the study correspond well with the market situation. Before the appearance of the mentioned crisis in the global and domestic market, there was a tendency of funds to remain in winner or loser groups in successive periods. During the evaluation of the fund market situation after the appearance of crisis, it was found (mainly by the application of the rates of return) that the analyzed entities changed their fund group affinity in relation to the median criterion.

The inference about the analyzed phenomenon in relation to the total horizon under study will be continued by adopting the second approach, connected with stochastic kernel estimation. The three-dimensional and two-dimensional space diagrams will present fund performance for the rates of return, Sharpe ratios and Treynor ratios.

The stochastic kernel mapping for annual performance is characterized by two stochastic kernel ridges for each of the three measures of return. The values' polarization of the density function of the probability distribution for successive pairs of returns in the total period under study, presented in the Figure 1, seems to be justified as far as the significant change in market tendencies within the analyzed time horizon is concerned. Moreover, the upper part of stochastic kernels' stratification suggests that the performance persistence thesis is roughly valid. However, the presence of the stochastic kernel ridge on the bottom of the diagrams could stand for performance reversal. This means that there are two main sub-periods, in which the adequate transitions of fund performance could have taken place, causing differences in performance dependence in consecutive periods. On that basis it is possible to search for similarities between the results obtained through the application of the traditional research method to the two sub-periods: 2007-2000 and 2007-2010. Nevertheless, the answer obtained by means of this method is equivocal. The strongest evidence for the existence of performance persistence phenomenon, provided by the arrangement of the stochastic kernel isolines along the line inclined at an angle of 45 degrees to the X-axis, might be noticed among the Sharpe ratios. Such a conclusion corresponds well with the results obtained for the total period under study through the application of the traditional research method.

\subsection{Six-month perspective}

Just as previously, the analysis of performance dependence in consecutive periods in a six-month perspective will be conducted by using two research methods. The applied measures of return will be the ratios of evaluating asset management most frequently mentioned in financial literature, which are namely the rate of return, Sharpe ratio and Treynor ratio. 


\section{Figure 1}

Layered Mapping of Stochastic Kernels and Contour Plots for Mutual Fund Performance in 1-Year Perspective

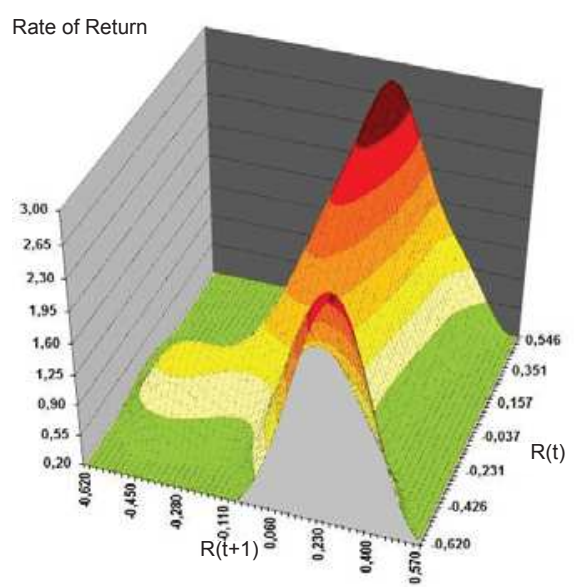

Rate of Return
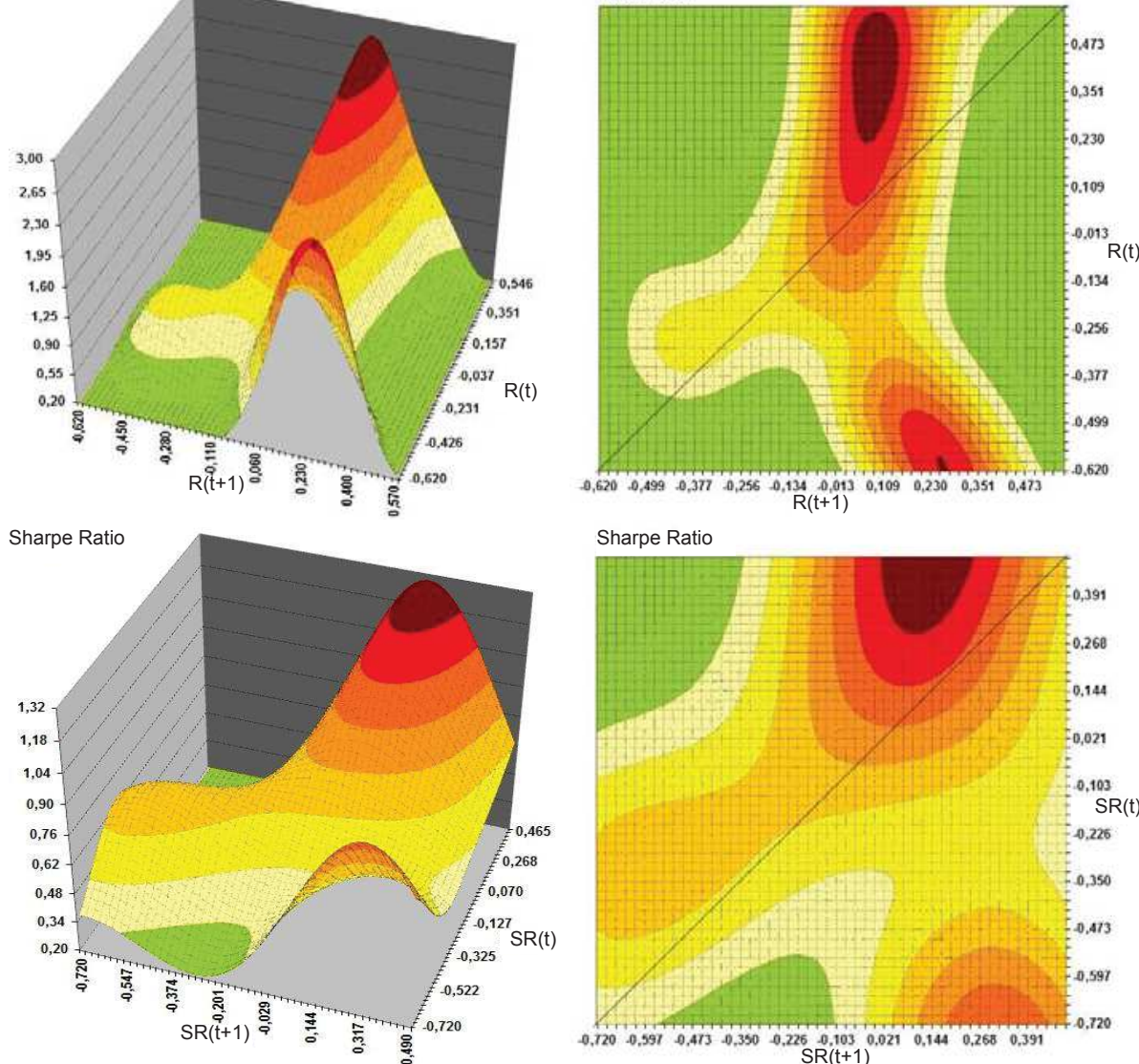

Sharpe Ratio
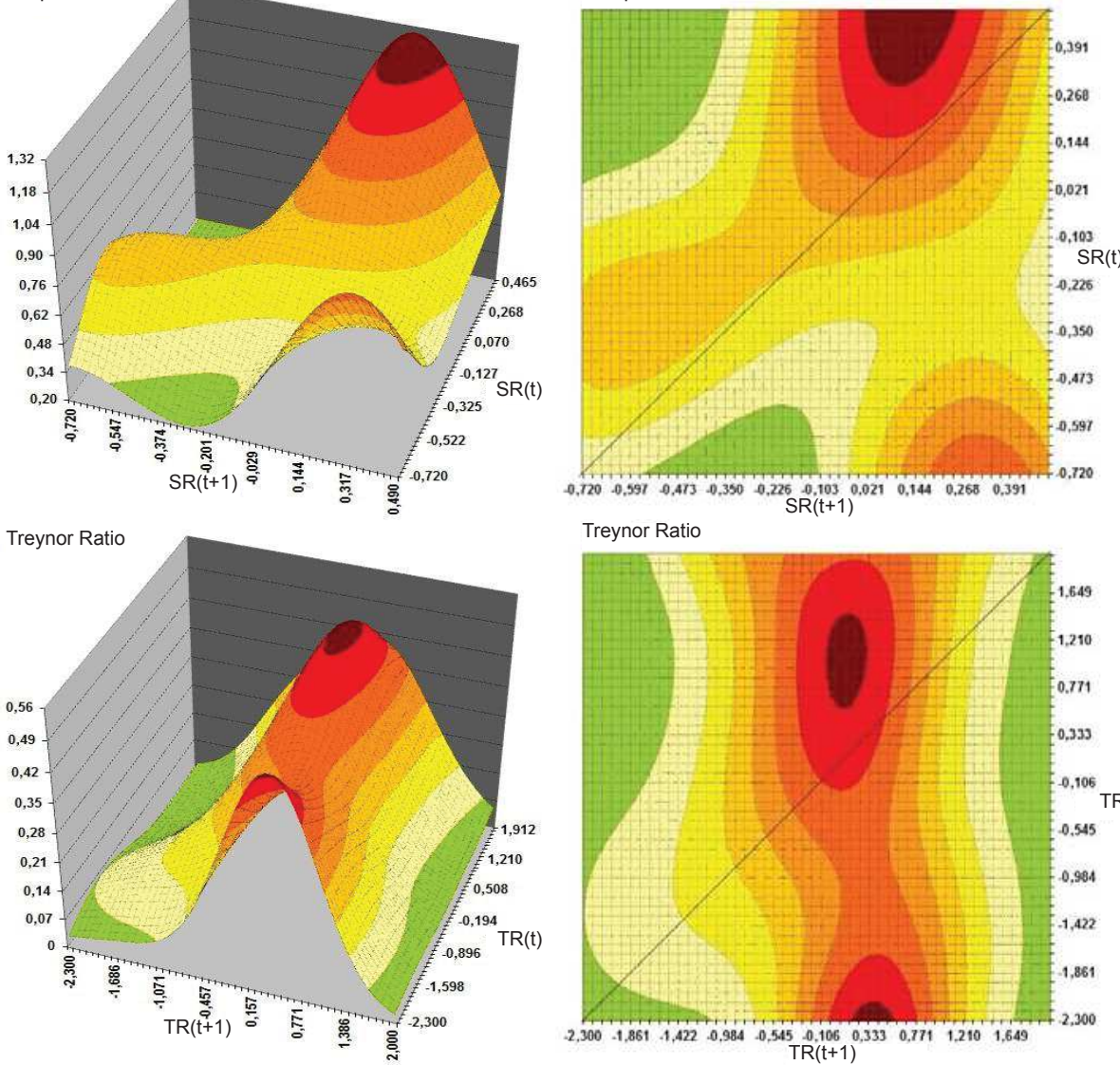

Treynor Ratio

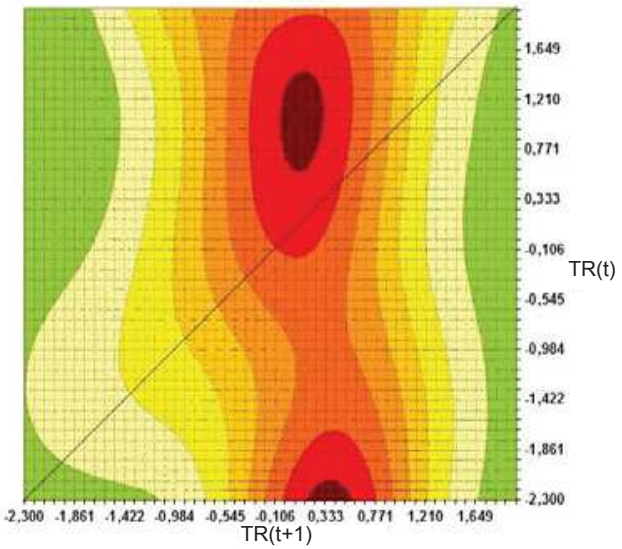

Source: own study. 
Table 3

\section{Results of Non-Parametric Tests Based on Contingency Tables in 6-Month Perspective}

\begin{tabular}{|c|c|c|c|c|c|c|c|c|c|c|}
\hline \multirow{2}{*}{$\begin{array}{l}\text { Measure } \\
\text { Periods }\end{array}$} & \multirow{2}{*}{$\begin{array}{l}\text { No. } \\
\text { of } \\
\text { ob- } \\
\text { serv. }\end{array}$} & \multicolumn{3}{|c|}{ Rate of Return } & \multicolumn{3}{|c|}{ Sharpe Ratio } & \multicolumn{3}{|c|}{ Treynor Ratio } \\
\hline & & $C P R$ & $z$ & $\mathrm{CHI}$ & $C P R$ & $z$ & $\mathrm{CHI}$ & $C P R$ & $z$ & $\mathrm{CHI}$ \\
\hline $2 \mathrm{nd}$ half of $2000 / 1$ st half of 2000 & 9 & 1,50 & 0,2995 & 0,3333 & 1,50 & 0,2995 & 0,3333 & 1,50 & 0,2995 & 0,3333 \\
\hline 1 st half of $2001 / 2$ nd half of 2000 & 11 & 1,50 & 0,3311 & 0,2727 & 8,00 & 1,4704 & 2,4545 & 8,00 & 1,4704 & 2,4545 \\
\hline $2 \mathrm{nd}$ half of 2001 / 1st half of 2001 & 18 & 1,56 & 0,4704 & 0,2222 & 0,25 & $-1,3863$ & 2,0000 & 0,64 & $-0,4704$ & 0,2222 \\
\hline 1 st half of 2002 / 2nd half of 2001 & 18 & 12,25 & **2,2097 & $* * 5,5556$ & 0,64 & $-0,4704$ & 0,2222 & 0,25 & $-1,3863$ & 2,0000 \\
\hline $2 \mathrm{nd}$ half of $2002 / 1$ st half of 2002 & 22 & 7,11 & $* * 2,0489$ & ${ }^{* *} 4,5455$ & 1,44 & 0,4258 & 0,1818 & 0,69 & $-0,4258$ & 0,1818 \\
\hline 1st half of 2003 / 2nd half of 2002 & 22 & 1,44 & 0,4258 & 0,1818 & 1,44 & 0,4258 & 0,1818 & 1,44 & 0,4258 & 0,1818 \\
\hline $2 \mathrm{nd}$ half of 2003 / 1st half of 2003 & 17 & 3,33 & 1,1844 & 1,5882 & 10,50 & $* \star 2,0548$ & **4,8824 & 3,33 & 1,1844 & 1,5882 \\
\hline 1st half of 2004 / 2nd half of 2003 & 15 & 2,22 & 0,7556 & 0,7333 & 0,75 & $-0,2764$ & 0,2000 & 2,22 & 0,7556 & 0,7333 \\
\hline 2 nd half of 2004 / 1st half of 2004 & 15 & 2,22 & 0,7556 & 0,7333 & 7,50 & *1,7235 & *3,4000 & 2,22 & 0,7556 & 0,7333 \\
\hline 1 st half of 2005 / 2nd half of 2004 & 15 & 0,75 & $-0,2764$ & 0,2000 & 0,75 & $-0,2764$ & 0,2000 & 0,24 & $-1,2850$ & 1,8000 \\
\hline $2 \mathrm{nd}$ half of $2005 / 1$ st half of 2005 & 14 & 1,78 & 0,5327 & 0,2857 & 1,78 & 0,5327 & 0,2857 & 1,78 & 0,5327 & 0,2857 \\
\hline 1st half of 2006 / 2nd half of 2005 & 14 & 0,56 & $-0,5327$ & 0,2857 & 6,25 & 1,5488 & 2,5714 & 6,25 & 1,5488 & 2,5714 \\
\hline $2 \mathrm{nd}$ half of $2006 / 1$ st half of 2006 & 14 & 1,78 & 0,5327 & 0,2857 & 1,78 & 0,5327 & 0,2857 & 1,00 & 0,0000 & 0,2857 \\
\hline 1st half of 2007 / 2nd half of 2006 & 15 & 1,33 & 0,2764 & 0,2000 & 1,33 & 0,2764 & 0,2000 & 7,50 & *1,7235 & * 3,4000 \\
\hline 2 nd half of 2007 / 1st half of 2007 & 16 & 0,20 & $-1,4692$ & 2,5000 & 21,00 & $* \star 2,2633$ & ${ }^{* *} 6,5000$ & 2,78 & 0,9892 & 1,0000 \\
\hline 1st half of $2008 / 2$ nd half of 2007 & 19 & 1,87 & 0,6752 & 0,5789 & 8,00 & $* * 1,9605$ & **4,7895 & 2,92 & 1,1123 & 1,8421 \\
\hline 2 nd half of $2008 / 1$ st half of 2008 & 21 & 0,25 & $-1,4820$ & *2,8095 & 2,63 & 1,0726 & 1,2857 & 0,55 & $-0,6641$ & 0,5238 \\
\hline 1st half of 2009 / 2nd half of 2008 & 24 & 0,51 & $-0,8127$ & 0,6667 & 1,00 & 0,0000 & 0,0000 & 0,71 & $-0,4092$ & 0,3333 \\
\hline 2 nd half of $2009 / 1$ st half of 2009 & 25 & 10,00 & **2,4577 & ${ }^{* * *} 6,8400$ & 2,24 & 0,9868 & 1,0800 & 1,17 & 0,1923 & 0,1200 \\
\hline 1st half of 2010 / 2nd half of 2009 & 25 & 1,17 & 0,1923 & 0,1200 & 0,61 & $-0,6074$ & 0,4400 & 0,31 & $-1,3902$ & 2,0400 \\
\hline 2nd half of $2010 /$ st half of 2010 & 25 & 0,15 & $* *-2,1276$ & **4,9200 & 0,31 & $-1,3902$ & 2,0400 & 2,24 & 0,9868 & 1,0800 \\
\hline $\begin{array}{l}\text { in period } 1 \text { st half of } 2000- \\
2 \text { nd half of } 2007\end{array}$ & 235 & 1,76 & $* * 2,1373$ & $* * 4,9489$ & 1,89 & $* * 2,4026$ & $* * 6,0383$ & 1,48 & 1,4857 & 2,6681 \\
\hline $\begin{array}{l}\text { in period } 1 \text { st half of } 2008- \\
2 \text { nd half of } 2010\end{array}$ & 139 & 0,86 & $-0,4273$ & 0,3669 & 1,29 & 0,7429 & 1,1151 & 0,96 & $-0,1126$ & 0,7698 \\
\hline total horizon $2000-2010$ & 374 & 1,35 & 1,4375 & 2,5775 & 1,64 & $* * 2,3611$ & ${ }^{* *} 6,2139$ & 1,26 & 1,1120 & 2,3636 \\
\hline
\end{tabular}

Note: ${ }^{*}{ }^{* *},{ }^{* * *}$ indicate statistical significance to reject the null hypothesis at respective levels: $10 \%, 5 \%$ and $1 \%$. The $n c$ symbol was used because of the lack of mutual funds classified to the WL or LW groups, which did not allow for calculation of CPR or Z-statistic. Source: own study. 
The examination of performance persistence phenomenon by means of contingency tables made it possible to calculate the $C P R$ ratio and conduct two statistical tests. The results obtained by using $Z$ - and $C H I$ statistics produced weak and only partial evidence for the existence of dependence of consecutive pairs of returns. The results were contingent upon the applied measure of return as in the case of 1-year perspective. The short-term persistence in 6-month periods was observed most often by means of the rate of return. However, the occurrence of the analyzed phenomenon in the total time period was confirmed only by the Sharpe ratio. In the two specified sub-periods of the 6-month perspective (before and after the end of 2007), the thesis about performance dependence in successive periods was also only partially confirmed. Contrary to the results from 1-year perspective, it has to be underlined that performance reversal was not found within the period of financial crisis. As for the results obtained by means of the Treynor ratio used for the 6-month perspective, they turned out to be generally insignificant, which may be due to the constraints on the database structure. The mean monthly rate of return and the standard deviation of the monthly rate of return in the Sharpe ratio case, as well as the Beta parameter for the Treynor ratio, were computed on the basis of six observations. Therefore, these last two measures of return should be taken cautiously.

The second of the applied research methods enables a graphical verification of the thesis about the occurrence of performance persistence. The analysis of the stochastic kernel stratification will be done as in the previous part of the paper by the application of the rates of return, Sharpe ratios and Treynor ratios respectively.

A higher number of observations in the 6-month perspective did not enhance the credibility of the thesis about the occurrence of performance persistence among equity funds in the Czech Republic. None of the mappings of graphically presented stochastic kernels conduced to prove the thesis about dependence of consecutive pairs of returns. A total or partial division of the stochastic kernel's ridge was observed for each of the measures, which may mean various dominant consecutive pairs of returns. The counter-clockwise rotation of the kernel in relation to the line inclined at an angle of 45 degrees to the X-axis implies the existence of convergence processes for the rates of return, Sharpe ratios and Treynor ratios. The convergences may occur in the case of performance of funds that maintain their group affiliation in consecutive periods. In general, it is difficult to conclude about the short-term persistence basing on the results mentioned above, all the more so that the classic methods do not confirm the phenomenon. 
Figure 2

Layered Mapping of Stochastic Kernels and Contour Plots for Mutual Fund Performance in 6-Month Perspective
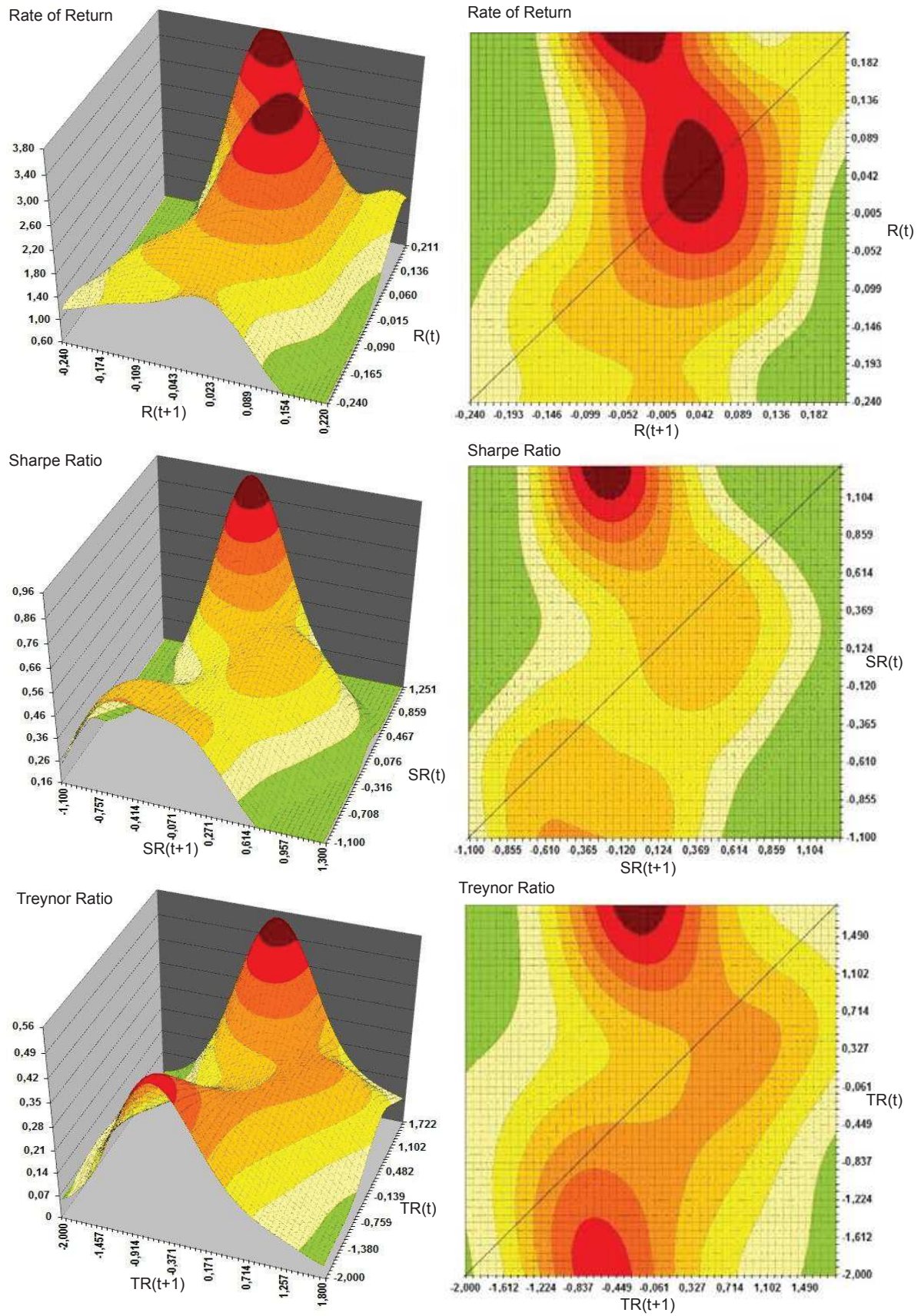

Source: own study. 


\subsection{Empirical results vs. financial market situation}

While summarizing the results discussed so far, it should be noticed that the applied methods provide evidence for the occurrence of strongly limited persistence of equity fund performance within the total period under study. Having specified the two separate sub-periods (before and after the appearance of crisis), we observed that both the rates of returns and the Sharpe ratios showed the periodic dependence. Hence, this finding can be linked with the market situation. The presentation of the tendencies in the Czech capital market (see Figure 3) allows to refer to the one of the premises of performance persistence occurrence, which is the constancy and similarity of investment strategies for certain subgroups of funds.

As presented in the Figure 3, the financial market entered a period of prosperity in 2002. From the second half of 2001 to the end of 2003, an average rate of the threemonth Treasury bills decrease accompanied a value of the PX index increase. At that time, the occurrence of performance persistence of equity funds took place in the given sub-periods. In the following years an upward tendency in the capital market was gathering momentum, but it was impossible to avoid several vital trend revisions of the main Prague Stock Exchange index, for instance. A rapid increase of equity markets did not go hand in hand with stability demanding performance persistence of investment funds. Moreover, a sudden harbinger of problems in the US market in the second half of 2007, which meant the occurrence of the global financial crisis - confirmed by S\&P500 index value decrease, entailed a reversal in the tendency both in the Czech capital and the money market. A performance reversal of equity funds, in turn, took place not until 2009, when the atmosphere in financial markets improved for several months. In general, the obtained results in the two separate sub-periods (2000-2007 and 2007-2010) correspond well with the market situation when we consider the appearance of the financial crisis as a critical point. However, explaining the results obtained in this study by the situation in the financial market may be justified in the case of short term perspectives but only to a certain extent.

According to Brown and Goetzmann (1995), one of the reasons of the performance persistence existence is a market situation. Having settled the actual economic situation at the moment of the occurrence of performance dependence in consecutive periods, one may help to determine the strength and character of the phenomenon. In general, the occurrence of performance persistence at the time of stabilized market tendency is due to the lack of significant changes in applied investment strategies of the analyzed entities. However, the character of performance persistence contingent upon particular market conditions is superficial. This could be confirmed by the occurrence of the second type of performance dependence, the so-called reversal, in the periods of shocks in financial markets. Hypothetically, the persistence of good (or bad) results in successive periods during the trend changes can be connected with managerial abilities of fund managers. However, the study concerning performance of the Czech equity funds, to which the present paper is related, provided no statistically significant evidence that would confirm 
attaining durable abnormal returns by fund managers. It is necessary to bear in mind that the Czech investment fund industry is quite a specific market with regard to its size and the number of the operated equities, which is still low. This combined with the slow development and the specific shallowness of the local financial market may cause the obtained results to differ from the findings resulting from the similar analyses from the other countries of the region.

Figure 3

The Values of the Stock Market Indices (left Y-axis data) and Average Rates of Czech T-Bill (right Y-axis data) from January 2000 to December 2010

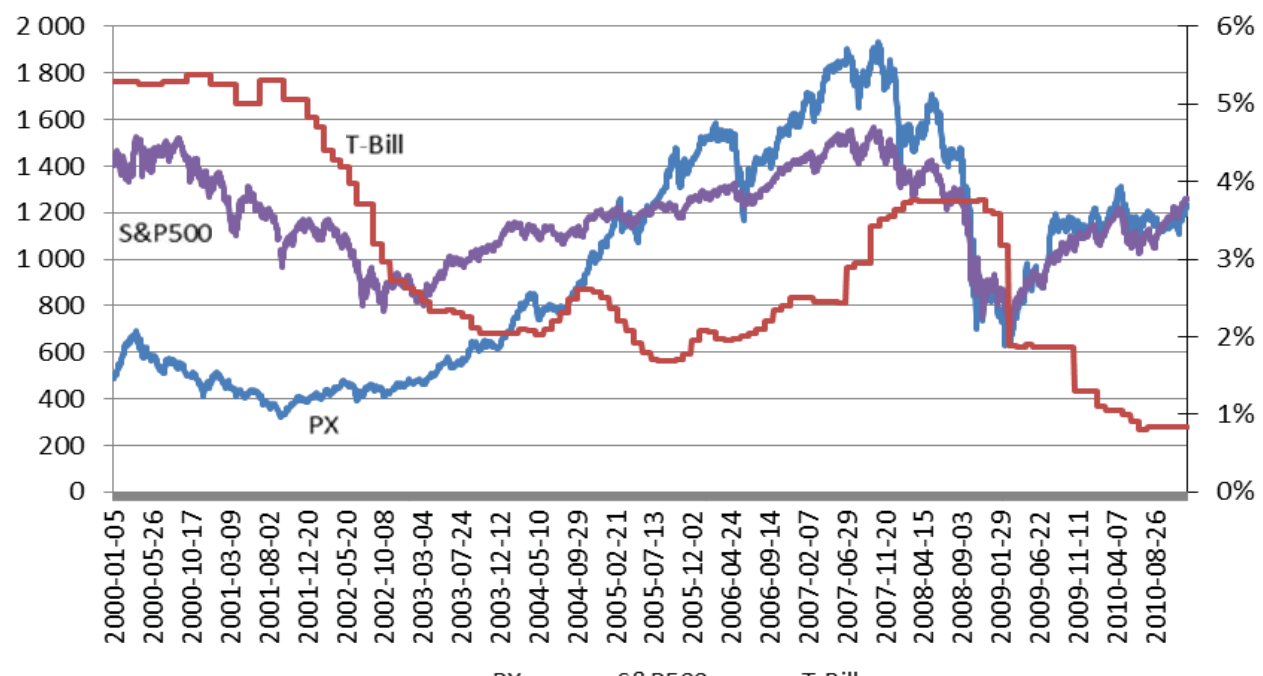

Source: own compilation on the basis of Prague Stock Exchange (PX), Standard\&Poor's (S\&P500) statistics and IMF International Financial Statistics database (T-Bill rate).

\section{Summary and Conclusions}

The practical aim of the present study was to verify the occurrence of persistence in the performance of the Czech collective investment companies. It was possible by the application of traditional contingency tables and the new approach discussed in financial literature and based on stochastic kernel estimation. The implementation of the second method allowed to partially fill the research gap as the number of similar studies in the CEE countries is relatively low. Furthermore, the application of numerous measures of return in the study and in the previous paper related to the present one (Filip, 2011), enables a comprehensive outlook on the performance of investment funds in the Czech Republic. The obtained results showed the existence of weak and limited performance persistence in 1-year and 6-month perspectives. It has to be noticed that the character of the mentioned persistence could be connected with the specificity of the Czech financial market as well as to the conditions for the development of investment fund industry. Such a conclusion was possible by using the Sharpe ratios for the total time period and 
the rates of return for the given sub-periods. In general, the strength of the analyzed phenomenon depended on the applied measure. Having specified the two sub-periods (before and after the appearance of the financial crisis), we were able to observe the existence of performance persistence in the first sub-period and a partial performance reversal in the second one. Therefore, performance dependence in consecutive periods might be related to the market situation.

In conclusion, the obtained results allow to refer to the situation in the investment fund market. Particularly at the time when the tendencies in the capital market were stable, the winning collective investment companies had the possibility to take advantage of favourable conditions in their marketing actions due to a high probability of achieving similar investment results in successive periods. Nevertheless, it is difficult to explain that kind of results by managerial skills.

\section{References}

Bers, M. K. (1998), "Causal Relations Among Stock Returns, Inflation: Persistence of International Mutual Fund Performance." Global Finance Journal, Vol. 9, No. 2, pp. 225-240.

Brown, S. J., Goetzmann, W. N. (1995), "Performance Persistence." The Journal of Finance, Vol. 50, No. 2, pp. 679-698.

Carhart, M. (1997), "On Persistence in Mutual Fund Performance." The Journal of Finance, Vol. 52, No. 1, pp. 57-82.

Christensen, M. (2005), "Danish Mutual Fund Performance. Selectivity, Market Timing and Persistence." Aarhus School of Business, Finance Research Group Working Paper No. F-2005-1. Available at SSRN: http://ssrn.com/abstract=670701.

Christensen, R. (1990), Log-Linear Models. New York: Springer-Verlag.

De Jorge, J. (2006), "Regional Regulation Analysis of Performance in Spanish Retailing." International Journal of Retail \& Distribution Management, Vol. 34, No. 10, pp. 773-793.

Detzel, F. L., Weigand, R. A. (1998), "Explaining Persistence in Mutual Fund Performance." Financial Services Review, Vol. 7, No. 1, pp. 45-55.

EFAMA (2011), "Trends in the European Investment Fund Industry in the Fourth Quarter of 2010 and Results for the Full Year 2010." Quarterly Statistical Release, February, No. 44: European Fund and Asset Management Association.

Fama, E. F., French, K. R. (1993), "Common Risk Factors in the Returns on Stocks and Bonds." Journal of Financial Economics, Vol. 33, No. 1, pp. 3-56.

Ferson, W., Schadt, R. (1996), "Measuring Fund Strategy and Performance in Changing Economic Conditions." Journal of Finance, Vol. 51, No. 2, pp. 425-462.

Fienberg, S. E. (1980), The Analysis of Cross-classified Categorical Data. Cambridge, Mass: MIT Press.

Filip, D. (2011), "The Analysis of Czech Investment Funds Performance." Ekonomické listy, No. 9, pp. 22-39.

Gallo, J. G., Lockwood, L. J., Swanson, P. E. (1997), "The Performance of International Bond Funds." International Review of Economics and Finance, Vol. 6, No. 1, pp. 17-35.

Hallahan, T. A. (1999), "The Information Content of Portfolio Performance History and Persistence in Fund Performance: An Examination of Rollover Funds." Accounting and Finance, Vol. 39, No. 3, pp. 255-274. 
Henriksson, R. D., Merton, R. C. (1981), "On Market Timing and Investment Performance. II. Statistical Procedures for Evaluating Forecasting Skills.” The Journal of Business, Vol. 54, No. 4, pp. 513-533.

Hyndman, R. J., Bashtannyk, D. M., Grunwald, G. K. (1996), "Estimating and Visualizating Conditional Densities." Journal of Computational \& Graphical Statistics, Vol. 5, No. 4, pp. 315-336.

Jackowicz, K., Kowalewski, O., Kozłowski, Ł. (2011), "The Short and Long Term Performance Persistence in the Central European Banking Industry." Contemporary Economics, Vol. 5, No. 4, pp. 2-14.

Jackowicz, K., Kozłowski, Ł. (2008), "Analiza dynamiki rozkładów rentowności banków komercyjnych w Polsce z użyciem jądra stochastycznego [Dynamics of profitability distribution: an analysis of commercial banks in Poland with the application of stochastic kernel]." In: Dziawgo, L., ed., Współczesne finanse. Stan i perspektywy rozwoju bankowości. Toruń: Wydawnictwo Naukowe UMK, pp. 325-334.

Jensen, M. (1968), "The Performance of Mutual Funds in the Period 1945-1964." Journal of Finance, Vol. 23, No. 1, pp. 389-416.

Jindrichovska, I. (2009), "Open-Ending Czech Closed-End Funds: Evidence from Transitional Market." Academy of Taiwan Business Management Review, Vol. 5, No. 2, pp. 94-111.

Kahn, R., Rudd, A. (1995), "Does Historical Performance Predict Future Performance?" Financial Analysts Journal, Vol. 51, No. 6 November/December, pp. 43-52.

Lillard, L. A., Willis, R. J. (1978), "Dynamic Aspects of Earning Mobility." Econometrica, Vol. 46, No. 5, pp. 985-1012.

Lintner, J. (1965), "The Valuation of Risk Assets and the Selection of Risky Investments in Stock Portfolios and Capital Budgets." The Review of Economics and Statistics, Vol. 47, No. 1, pp. 13-37.

Madura, J., Bers, M. K. (2002), "The Performance Persistence of Foreign Closed-End Funds." Review of Financial Economics, Vol. 11, No. 4, pp. 263-285.

Otten, R., Bams, D. (2002), "European Mutual Fund Performance." European Financial Management, Vol. 8, No. 1, pp. 75-101.

Quah, D. (1997), "Empirics for Growth and Distribution; Stratification, Polarization and Convergence Clubs." Journal of Economic Growth, Vol. 2, No. 1, pp. 27-59.

Rosenblatt, M. (1969), "Conditional Probability Density and Regression Estimators." In: Krishnaiah, P.R., ed., Multivariate Analysis II. New York: Academic Press, pp. 25-31.

Scott, D. W. (1992), Multivariate Density Estimation. Theory, Practice, and Visualization. New York, Chichester, Brisbane, Toronto, Singapore: A Wiley-Interscience Publication, John Wiley \& Sons, Inc.

Sharpe, W. F. (1964), "Capital Asset Prices - A Theory of Market Equilibrium under Conditions of Risk." Journal of Finance, Vol. 19, No. 3, pp. 425-442.

Sharpe, W. F. (1966), "Mutual Funds Performance." Journal of Business, Vol. 39, No. 1, pp. 119-138.

Treynor, J. L. (1965), "How to Rate Management of Investment Funds.' Harvard Business Review, Vol. 43, No. 1, pp. 63-75.

Treynor, J., Mazuy, K. (1966), "Can Mutual Fund Outguess the Market?" Harvard Business Review, Vol. 44, No. 4, pp. 131-136. 